\title{
Foaming Behaviour, Structure, and Properties of Polypropylene Nanocomposites Foams
}

\author{
M. Antunes, V. Realinho, and J. I. Velasco \\ Departament de Ciència del Materials i Enginyeria Metal.lúrgica, Centre Català del Plàstic, Universitat Politècnica de Catalunya, \\ C/ Colom 114, 08222 Terrassa, Barcelona, Spain
}

Correspondence should be addressed to J. I. Velasco, jose.ignacio.velasco@upc.edu

Received 30 November 2009; Revised 25 February 2010; Accepted 2 April 2010

Academic Editor: Frank T. Fisher

Copyright ( $) 2010$ M. Antunes et al. This is an open access article distributed under the Creative Commons Attribution License, which permits unrestricted use, distribution, and reproduction in any medium, provided the original work is properly cited.

This work presents the preparation and characterization of compression-moulded montmorillonite and carbon nanofibrepolypropylene foams. The influence of these nanofillers on the foaming behaviour was analyzed in terms of the foaming parameters and final cellular structure and morphology of the foams. Both nanofillers induced the formation of a more isometric-like cellular structure in the foams, mainly observed for the MMT-filled nanocomposite foams. Alongside their crystalline characteristics, the nanocomposite foams were also characterized and compared with the unfilled ones regarding their dynamic-mechanical thermal behaviour. The nanocomposite foams showed higher specific storage moduli due to the reinforcement effect of the nanofillers and higher cell density isometric cellular structure. Particularly, the carbon nanofibre foams showed an increasingly higher electrical conductivity with increasing the amount of nanofibres, thus showing promising results as to produce electrically improved lightweight materials for applications such as electrostatic painting.

\section{Introduction}

Although the increasing interest in the preparation and study of polyolefin foams, there is still lack of information regarding the characterization of rigid polypropylene foams thought for structural applications with typical relative densities, that is, the density of the foam divided by that of the respective solid, higher than 0.1 . Hence the interest in preparing and studying new polypropylene-based foams by carefully controlling the expansion and final cellular structure [1].

Nowadays, the use of low-density PP foams is rather limited when compared to PE to situations where higher service temperatures or thermal stabilities are required. PE is cheaper and displays a wider range of molecular architectures, making it easier to reach the high melt strengths and extensibilities required for foaming. Also, the rubbery plateau of the polymer melt can be easily increased via crosslinking, that way it wides the optimum temperature window for stable foam production [1]. Contrarily, PP's linear structure makes it harder to foam due to its intrinsically low melt strength [2]. In order to achieve the high expansions required for applications such as packaging, PP is often blended with other polyolefins, mainly low melting point ethylene copolymers such as EVA or ethylene-octene copolymers [3] or used as random copolymer with low ethylene content [4].

Some of the advantages of PP, such as its higher stiffness, strength, and better impact strength, only start to be relevant at higher foam densities $\left(\rho>100 \mathrm{~kg} / \mathrm{m}^{3}\right)$. That is why medium density PP foams have been considered in this work. Nevertheless, even at these relatively high densities, the use of PP requires the improvement of its melt resistance. This was possible with the development of long-chain branching modified grades, conventionally known as high melt strength polypropylenes (HMS-PP). The use of these polypropylenes has been shown to improve the volume expandability and cell uniformity, retard cell coalescence, and increase the expansion ratio, globally broadening the optimum foaming processing window $[5,6]$.

Four basic foaming processes are commonly used to produce PP foams: (1) direct extrusion, where a foam is directly obtained by sudden decompression at the exit of an extrusion die $[7,8]$; (2) injection, where expansion is adjusted inside a closed injection mould; (3) compression 
moulding, where the material is foamed by simultaneously applying heat and pressure and later expanding the material by sudden decompression, conventionally using exothermic chemical blowing agents such as azodicarbonamide (ADC) [9]; (4) batch foaming, where the material is foamed by initially dissolving $\mathrm{N}_{2}$ or $\mathrm{CO}_{2}$ in the solid polymer inside high pressure reactors and afterwards expanding the material by heating at low pressure above the glass transition temperature of the polymer-gas mixture or by sudden pressure drop [10-12].

Due to its versatility, compression moulding was used in this work for the preparation of the medium-density polypropylene foams. It is a process that allows to control the expansion by varying the amount of ADC and processing parameters. Therefore, it enables the analysis of incorporating nanometric-sized reinforcements on the foaming behaviour, cellular structure, and final properties of the material and the effect of the foaming process on the particles' distribution and dispersion $[6,13]$. With the disadvantage of presenting solid residues inherent to the thermal decomposition of ADC or an anisotropic cellular distribution with cells smaller close to the surface, foams produced using this technique may reach thicknesses as high as $10 \mathrm{~cm}$ with cell sizes in the micrometer range [8]. Comparatively, gas dissolution is a very time-consuming process due to the high times required for dissolving the gas, and the Mucell injection foaming process is rather limited to high density foams $\left(>300 \mathrm{~kg} / \mathrm{m}^{3}\right)$ [14]. Albeit the small moulds used in this work, these can be easily scaled-up to produce very complex foamed elements and components by replacing the mould, while in the case of injection, mould replacement would be very costly.

During the last couple of years, polymer nanocomposite foams have received increasing attention in both scientific and industrial communities [15]. It has been proven that small amounts of finely-dispersed nanoparticles may act as sites for bubble nucleation during the foaming process. Particularly, the cell density has been found to increase linearly with the clay concentration for low clay values $[16,17]$. Besides, the highest cell density was obtained when the clay platelets were exfoliated, attained to a higher effective particle concentration and thus higher nucleation efficiency $[16,18]$. In accordance with the higher cell densities, smaller cell sizes were obtained in the presence of the nanoparticles. Thus, the presence of exfoliated nanoparticles may result in finer cellular structures due to a combined bubble nucleation and melt strain hardening effects [19]. The nanometric size of the particles also increases the interaction with the polymer matrix, offering a high potential for local reinforcement, resulting in macroscopic mechanical enhancements. If one considers the micrometer or submicrometer thickness of the cell walls in foams, the extremely small size of the nanoparticles could locally act reinforcing them. In the case of layered-like nanoparticles such as montmorillonite, good barrier properties can also be expected by the nanosizedplatelets limiting gas diffusion during the expansion and stabilization of the foam [15].

Several works have compared the mechanical properties of PVC and PS nanocomposite foams with that of the respective unfilled ones under tensile and compressive conditions $[18,20]$. In all cases, using layered silicates such as montmorillonite or carbon nanofibres resulted in higher moduli and tensile strengths; in some cases the nanocomposite foams even display higher specific moduli than the solid unfilled material [21].

Therefore, the specific properties of the foams could be extended with the incorporation of low amounts of functional inorganic phases with high specific surface areas. With that in mind, two types of nanometric-sized reinforcements, montmorillonite, MMT $[6,22]$ and different amounts of carbon nanofibres, CNF [23, 24], were added to a PP-based foaming formulation, the nanocomposite materials later chemically foamed by compression moulding. The particular case of incorporating conductive nanofillers such as carbon nanofibres could result in the improvement of properties such as the electrical conductivity [25], thus contributing to the development of new lightweight electrically conductive materials.

\section{Materials and Compounding}

2.1. Nanocomposite Preparation. A PP material specifically formulated for foaming applications, referred to as PP, was prepared by meltcompounding using a corotating twinscrew extruder (Collin Kneter 25X36D, L/D = 36), 50 phr of a $\mathrm{PP}-\mathrm{HMS}$, and $50 \mathrm{phr}$ of an extrusion grade-type with stearic acid $(0.2 \mathrm{phr})$, talc $(1.0 \mathrm{phr})$, and two different amounts of a chemical blowing agent, azodicarbonamide (1.5 and $3.5 \mathrm{phr}$ ). These two concentrations of ADC were used to reach the desired expansion ratios. A constant temperature of $165^{\circ} \mathrm{C}$ and screw speed of $160 \mathrm{rpm}$ were used for all the materials.

The PP-HMS used was an especially modified longchain branched PP with a density of $0.902 \mathrm{~g} \cdot \mathrm{cm}^{-3}$ and melt flow index (MFI) of $2.1 \mathrm{~g} / 10 \mathrm{~min}$ at $230^{\circ} \mathrm{C}$ and $2.16 \mathrm{~kg}$. The linear extrusion-grade type of PP had a density of $0.905 \mathrm{~g} \cdot \mathrm{cm}^{-3}$, and MFI of $5.8 \mathrm{~g} / 10 \mathrm{~min}\left(230^{\circ} \mathrm{C}\right.$ and $\left.2.16 \mathrm{~kg}\right)$. The azodicarbonamide (Porofor ADC/M-C1), with an ADC content of $99.1 \%$, a density of $1.65 \mathrm{~g} \cdot \mathrm{cm}^{-3}$ and an average particle size of $3.9 \pm 0.6 \mu \mathrm{m}$, was added to the polymer blend in the extruder.

In the case of the montmorillonite nanocomposite, a commercial masterbatch of 75 wt. $\%$ of PP with 25 wt.\% of an octadecyl amine modified montmorillonite (Nanomer $\mathrm{C} 32 \mathrm{P}$ ) was melt-compounded with the PP material in the extruder so as to obtain a final nanocomposite with $5.0 \mathrm{phr}$ of the modified montmorillonite (PP-MMT).

Three different carbon nanofibre-polypropylene nanocomposites (PP-CNF) were prepared by melt mixing in the twin screw extruder 5, 10, and $20 \mathrm{wt} . \%$ of carbon nanofibres with the previously mentioned PP matrix. The carbon nanofibres used in this work were highly graphitized submicron vapour grown carbon nanofibres, with a typical diameter of $20-80 \mathrm{~nm}$, fibre length $>30 \mu \mathrm{m}$, density of $1.97 \mathrm{~g} \cdot \mathrm{cm}^{-3}$, specific surface area BET $\left(\mathrm{N}_{2}\right)$ of $150-200 \mathrm{~m}^{2} \cdot \mathrm{g}^{-1}$, and electrical resistivity of $10^{-3} \Omega \cdot \mathrm{m}$. The reason behind the preparation of these three nanocomposites 


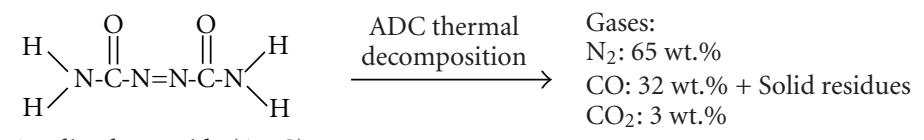

Azodicarbonamide (ADC)

(a)

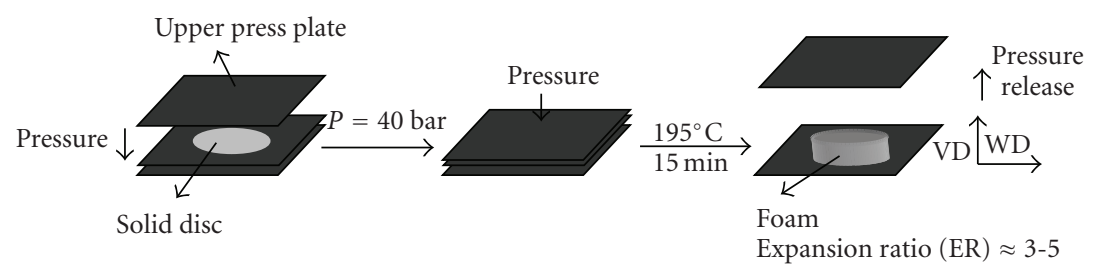

(b)

Figure 1: (a) Thermal decomposition of the ADC and (b) one-step compression moulding foaming process schematic. VD: Vertical direction of foaming; WD: Width direction.

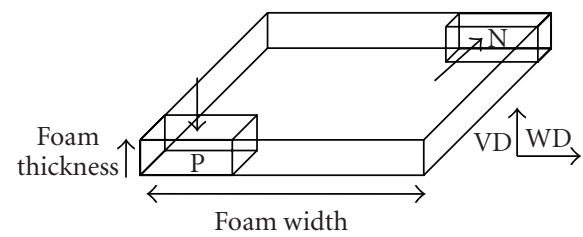

(a)

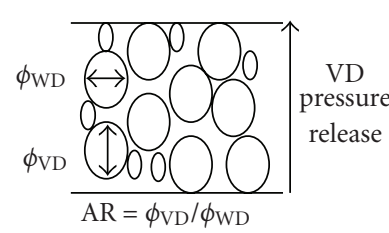

(b)

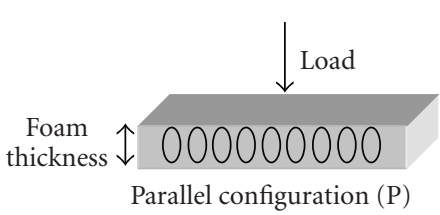

(c)

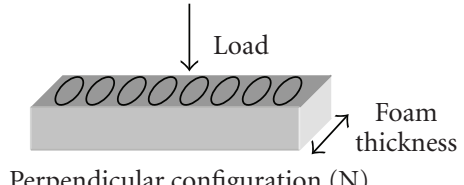

Perpendicular configuration $(\mathrm{N})$

(d)

FIGURE 2: (a) Schematic showing specimen configurations; (b) characteristic cellular structure parameters; (c) parallel (P); (d) perpendicular (N) specimen configurations.

lies on the interest in studying the electrical conductivity as a function of the amount of nanofibres.

The rather low processing temperatures $\left(165^{\circ} \mathrm{C}\right)$ and high screw speeds $(160 \mathrm{rpm})$ prevented the azodicarbonamide from thermally decomposing inside the extruder.

2.2. Foaming Process. Prior to foaming by thermal decomposition of the ADC (Figure 1(a)), solid discs of the different materials with a thickness of $3.5 \mathrm{~mm}$ and diameter of $74 \mathrm{~mm}$ were prepared by compression moulding the extruded pellets in a hot-plate press IQAP-LAP PL-15.

A one-step compression moulding process was used to foam the solid discs by placing them inside a circular mould $(\Phi=74 \mathrm{~mm})$ and heating at $195^{\circ} \mathrm{C}$ applying a pressure of 40 bar for 15 min using the hot-plate press (see Figure 1(b)).

2.3. Testing Procedure. Density of the several solids and foams was measured according to standard procedures (ISO $845)$.

The cellular structure of the foams was analyzed by scanning electron microscopy, SEM (JEOL JSM-5610). Samples were fractured at low temperature and made conductive by depositing a thin layer of gold. The average cell size $(\phi)$ and cell density were obtained using the intercept counting method [26]. Two different cell sizes were determined using the procedure presented in [13]: $\phi_{\mathrm{VD}}$ (VD: Vertical Direction), that is, the average cell size in the direction of pressure release and $\phi_{\mathrm{WD}}$ (Width Direction). The aspect ratio, AR $\left(\mathrm{AR}=\phi_{\mathrm{VD}} / \phi_{\mathrm{WD}}\right)$, was determined using a representative cell population. Schematics showing specimen configurations and most characteristic cellular structure parameters are presented in Figure 2.

The morphology of the foamed nanocomposites was assessed from high-magnification SEM micrographs and using transmission electron microscopy, TEM (HITACHI H800 ). For TEM, sheets with a typical thickness of $60 \mathrm{~nm}$ were cut using an ultramicrotome Ultracut E from Reichert-Jung.

Differential scanning calorimetry (DSC) was used to study the thermal characteristics of the matrix. A Perkin Elmer, Pyris 1 model with a glycol-based Perkin Elmer Intracooler IIP calorimeter was employed with samples weighting around $8.0 \mathrm{mg}$. The following program was used: heating from 30 to $200^{\circ} \mathrm{C}$ at $10^{\circ} \mathrm{C} / \mathrm{min}$ and holding for $1 \mathrm{~min}$ to erase the thermal history, followed by cooling at $10^{\circ} \mathrm{C} / \mathrm{min}$ from $200^{\circ} \mathrm{C}$ to $30^{\circ} \mathrm{C}$ and a second heating from 30 
TABLE 1: Cellular characterization results of the unfilled (PP), montmorillonite (PP-MMT), and carbon nanofibre (PP-CNF) polypropylene foams.

\begin{tabular}{lcccccccc}
\hline Code & Foam density $\left(\mathrm{kg} \cdot \mathrm{m}^{-3}\right)$ & $V_{\text {gas }}$ & $V_{\mathrm{PP}}$ & $V_{\mathrm{p}}$ & $\phi_{\mathrm{VD}}(\mu \mathrm{m})$ & $\phi_{\mathrm{WD}}(\mu \mathrm{m})$ & $A R$ & ${\text { Cell density }\left(\mathrm{cells} \cdot \mathrm{cm}^{-3}\right)}$ \\
\hline & $346 \pm 9$ & 0.62 & 0.38 & - & $194 \pm 7$ & $175 \pm 1$ & 1.1 & $4.71 \times 10^{4}$ \\
PP & $311 \pm 9$ & 0.66 & 0.34 & - & $177 \pm 2$ & $196 \pm 1$ & 0.9 & $4.63 \times 10^{4}$ \\
& $268 \pm 6$ & 0.71 & 0.29 & - & $241 \pm 9$ & $266 \pm 12$ & 0.9 & $3.52 \times 10^{4}$ \\
& $261 \pm 13$ & 0.72 & 0.29 & - & $243 \pm 14$ & $239 \pm 2$ & 1.0 & $3.42 \times 10^{4}$ \\
& $236 \pm 7$ & 0.75 & 0.25 & - & $456 \pm 5$ & $479 \pm 10$ & 1.0 & $1.30 \times 10^{4}$ \\
& $189 \pm 8$ & 0.80 & 0.20 & - & $564 \pm 6$ & $523 \pm 11$ & 1.1 & $9.13 \times 10^{3}$ \\
\hline PP-MMT & $256 \pm 8$ & 0.72 & 0.28 & 0.003 & $146 \pm 3$ & $160 \pm 7$ & 0.9 & $9.01 \times 10^{4}$ \\
& $245 \pm 5$ & 0.73 & 0.27 & 0.003 & $169 \pm 13$ & $156 \pm 12$ & 1.1 & $8.78 \times 10^{4}$ \\
& $240 \pm 10$ & 0.74 & 0.26 & 0.003 & $190 \pm 12$ & $164 \pm 15$ & 1.2 & $6.56 \times 10^{4}$ \\
PP-CNF & $238 \pm 12$ & 0.74 & 0.25 & 0.003 & $296 \pm 7$ & $211 \pm 4$ & 1.4 & $3.57 \times 10^{4}$ \\
& $220 \pm 7$ & 0.76 & 0.24 & 0.003 & $218 \pm 6$ & $204 \pm 8$ & 1.1 & $4.19 \times 10^{4}$ \\
& $208 \pm 4$ & 0.78 & 0.22 & 0.003 & $289 \pm 12$ & $206 \pm 6$ & 1.4 & $3.98 \times 10^{4}$ \\
& $176 \pm 3$ & 0.81 & 0.19 & 0.002 & $410 \pm 12$ & $293 \pm 12$ & 1.4 & $1.97 \times 10^{4}$ \\
\hline
\end{tabular}

to $200^{\circ} \mathrm{C}\left(10^{\circ} \mathrm{C} / \mathrm{min}\right)$. The crystallinity percentage $\left(X_{\mathrm{c}}\right)$ was determined according to

$$
X_{\mathrm{c}}(\%)=\frac{\Delta H_{m}}{\Delta H_{m}^{0} w_{\mathrm{p}}} \times 100,
$$

where $w_{\mathrm{p}}$ is the weight fraction of PP, $\Delta H_{m}$ is the melting enthalpy of the sample and $\Delta H_{m}^{0}$ the theoretical, $100 \%$ crystalline polypropylene enthalpy (207.1 J/g [27]).

Polypropylene's crystalline characteristics were analyzed by wide angle X-ray scattering (WAXS). A Bruker D8 diffractometer with $\mathrm{CuK} \alpha$ radiation $(\lambda=0.154 \mathrm{~nm})$ operating at $45 \mathrm{kV}$ and $40 \mathrm{~mA}$ was used. Scans were taken from 1 to $60^{\circ}$ with a rotation step of $0.033^{\circ}$ and a step time of $0.06 \mathrm{~s}$.

Dynamic mechanical analysis (DMA) was used to measure the dynamic-mechanical properties and study the viscoelastic behaviour of the several foamed nanocomposites. A TA Instruments Q800 Dynamic Mechanical Analyzer was used and calibrated according to the standard procedure. The glass transition temperature $\left(T_{\mathrm{g}}\right)$, storage modulus $\left(E^{\prime}\right)$, and loss factor $(\tan \delta)$ were obtained in a three-point bending configuration using a span length of $50.00 \mathrm{~mm}$. Two configurations, parallel $(\mathrm{P})$ and perpendicular $(\mathrm{N})$, respectively shown in Figures 2(c) and 2(d), were considered. Experiments were performed from -20 to $150^{\circ} \mathrm{C}$ at $2^{\circ} \mathrm{C} / \mathrm{min}$ and $1 \mathrm{~Hz}$. A static strain of $2 \%$ and dynamic of $0.02 \%$ with a preload force of $0.01 \mathrm{~N}$ and force track of $120 \%$ were chosen. Test specimens were prepared in a prismatic shape (see Figures 2(c) and 2(d)) with a nominal length of 55.00 $\pm 0.10 \mathrm{~mm}$, width of $13.00 \pm 0.10 \mathrm{~mm}$, and thickness of $3.00 \pm 0.05 \mathrm{~mm}$ (solids) and $3.50 \pm 0.10 \mathrm{~mm}$ (foams). Three experiments were performed for each material. The values reported in the text $\left(T_{\mathrm{g}}, E^{\prime}\right.$, and $\left.\tan \delta\right)$ are the average of these three experiments, and in all cases the standard deviation was lower than $5 \%$.
The electrical conductivity of the several solid and foamed PP-CNF nanocomposites was measured as a function of frequency between $10^{-2}$ and $10^{6} \mathrm{~Hz}$ using a Novocontrol impedance analyzer (HP 4192 A LF). A typical thickness of $130 \mu \mathrm{m}$ and $1.5 \mathrm{~mm}$ was, respectively, used for the solid and foams. All the measurements were made by previously gold-coating the surfaces of the samples, as it has previously been shown to directly affect the measurement of the electrical conductivity [23]. Five experiments were performed for each material, in all cases the standard deviation being lower than $3 \%$.

\section{Results and Discussion}

3.1. Foaming Behaviour and Cellular Structure. The material's code, density and respective gas $\left(V_{\text {gas }}\right)$, polypropylene $\left(V_{\mathrm{PP}}\right)$ and filler $\left(V_{\mathrm{p}}\right)$ volume fractions are presented in Table 1 alongside the most characteristic cellular structure results for all the foams.

As expected, the average cell size in VD and WD directions increased with foaming $\left(>V_{\text {gas }}\right)$. Results show that the cell size of the unfilled PP foams increased a lot faster than the PP-MMT ones for $V_{\text {gas }}$ between 0.70 and 0.80 (between $250-550 \mu \mathrm{m}$ for the first and $\approx 150-300 \mu \mathrm{m}$ for the second, determined as the average of the cell sizes on both direections). The MMT particles reduced the cell sizes (compare Figure 3(a) with Figure 3(c)) and narrowed the cell size distribution (AR closer to 1). The nanoparticles acted as bubble nucleators in the early stages of foaming, locally increasing the melt strength and extensibility of the polymer, thus explaining the increasingly higher cell size differences between both foams.

A good intercalation/exfoliation of the nanoparticles was mainly obtained after foaming the material (see arrows 


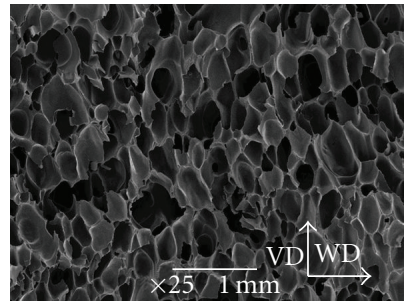

(a)

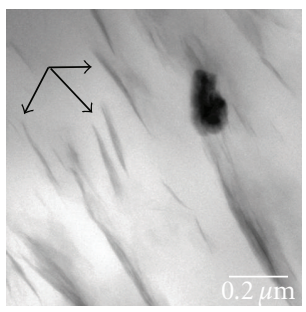

(d)

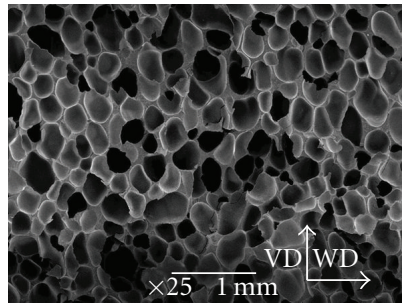

(b)

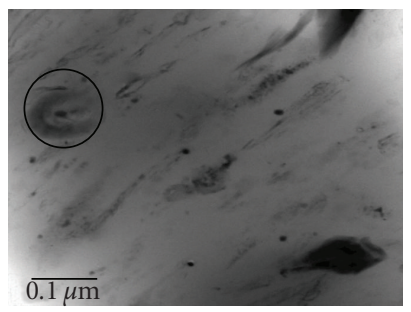

(e)

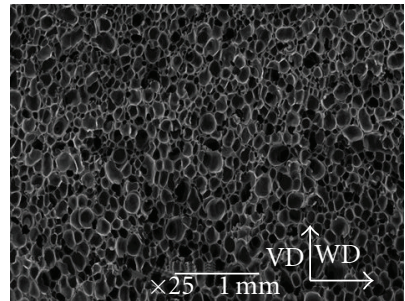

(c)

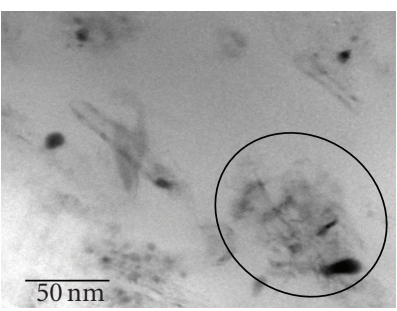

(f)

Figure 3: Typical SEM micrographs $(\times 25)$ of the (a) unfilled PP, (b) PP-CNF, and (c) PP-MMT nanocomposite foams; (d) typical TEM picture showing partial exfoliation of the MMT platelets; (e) and (f) TEM pictures showing CNF dispersion. VD: Vertical direction of foaming; WD: Width direction.

showing partially exfoliated MMT platelets in Figure 3(d) and the WAXS results shown later), thus supporting earlier results stating that foaming could come as a useful tool to exfoliate platelet-like structures such as montmorillonite $[6,16]$.

In the case of the carbon nanofibre-reinforced foams (PP-CNF), the cell size decreased for similar volume gas fractions with adding increasingly higher amounts of carbon nanofibres (see Table 1). Besides, the carbon nanofibres contributed to the formation of an isotropic cellular structure, that is, foams with aspect ratios close to 1 . For similar expansion ratios $\left(V_{\text {gas }} \approx 0.70\right)$, a considerable cell size reduction was observed with increasing the amount of nanofibres from 550 to $250 \mu \mathrm{m}$, respectively, for the 10 and 20 wt.\% CNF foams. A typical SEM micrograph displaying the cellular structure of the PP-CNF foams is presented in Figure 3(b).

Also presented in Figure 3 are two TEM pictures obtained at different magnifications showing the dispersion of the carbon nanofibres in the PP matrix (Figures 3(e) and 3(f)). Although some aggregates were observed (see black circles), these were a lot scarcer than in similar thermoplastic carbon nanotube-reinforced composites [28], thus supporting the combined efficiency of the melt-mixing and foaming processes.

3.2. Effects on the Crystalline Characteristics. The X-ray scattering analysis allowed studying eventual effects induced by the foaming process and incorporation of both types of nanofillers on polypropylene's crystallinity. Typical WAXS spectra of the solid and foamed nanocomposites are shown in Figure 4.

A considerable intensity shift from polypropylene's (040) diffraction peak towards the (110) was found with foaming for all the materials. The intensity ratio between peaks, $I(040) / I(110)$, decreased for the unfilled PP from around 4 for the solid to 1.5 for the foam. A remarkable further decrease was found with foaming the nanocomposites: 1.4 to 0.9 and 1.5 to 0.9 , respectively, for the MMT and CNF nanocomposite foams. This ratio is directly related to the arrangement of the $b$ lattice parameter of the $\alpha$-monoclinic polypropylene crystal, a higher value being indicative of a preferential orientation parallel to the sample's surface [29]. Despite the crystal anisotropy induced during the preparation of the solid discs, especially noticeable for the unfilled material $(I(040) / I(110) \approx 4)$, foaming reduced this preferential crystal orientation. Especially relevant is the fact that foaming totally erased all possible crystal orientation in the case of the nanocomposites $(I(040) / I(110) \approx 1)$.

Concerning polypropylene's crystallinity, the differences observed between the unfilled materials and the nanocomposites show that there is a less $\alpha$-crystal perfection in the pure PP foams than that in the solid (lower values of the full width at half maximum, FWHM). Contrarily, the nanoparticles promoted a higher crystalline perfection (lower FWHM values for the foams).

WAXS spectra were also used to ascertain the efficiency of the melt-mixing and foaming processes in guaranteeing an intercalated/exfoliated MMT nanocomposite morphology. Analyzing the (001) MMT peak, a lower diffraction angle was obtained for the foamed nanocomposite compared to its solid counterpart, indicating an increase in the interlayer distance $\left(d_{001}\right)$ from $2.99 \mathrm{~nm}$ to $4.01 \mathrm{~nm}$. Nevertheless, the foaming process was not enough to promote a total exfoliation of the montmorillonite particles. Despite the decrease in intensity, the (001) peak still appeared for the foamed nanocomposite, as seen in Figure 4(b). In good agreement, TEM analysis showed that the typical morphology of the 
foamed MMT nanocomposites consisted of mixed dispersed individual montmorillonite and stacks of montmorillonite platelets (see Figure 3(d)).

The PP-MMT nanocomposites showed a higher crystallization temperature and crystallinity than the unfilled polymer measured by DSC, indicating that the welldispersed nanoparticles acted nucleating crystals. The same type of nucleating effect was observed with incorporating the carbon nanofibres, mainly noticeable for the higher amounts. Higher crystallization temperatures were observed with adding the montmorillonite nanoparticles as well as the carbon nanofibres: from 130.2 and $126.7^{\circ} \mathrm{C}$ corresponding, respectively, to the beginning and maximum of the crystallization peak of the unfilled PP to 135.3 and $132.9^{\circ} \mathrm{C}$ for the PP-MMT nanocomposite and 135.6 and $131.8^{\circ} \mathrm{C}$ for the 20 wt.\% CNF material. In the case of the PP-CNF nanocomposites, the crystallization temperature measured at the maximum steadily increased around $2{ }^{\circ} \mathrm{C}$ with adding the nanofibres: from the $126.7^{\circ} \mathrm{C}$ of $\mathrm{PP}$, to $128.8^{\circ} \mathrm{C}(5$ wt.\% CNF), $129.6^{\circ} \mathrm{C}(10$ wt. $\% \mathrm{CNF})$, and $131.8^{\circ} \mathrm{C}(20$ wt.\% CNF). The crystallinity increased from the $46.2 \%$ of the material without nanofiller to $49.0 \%$ for the PP-MMT nanocomposite and 46.5, 48.9, and 49.6\%, respectively, for the 5, 10, and 20 wt.\% CNF materials. See Figure 5 for comparison between the unfilled and 20 wt.\% CNF foams.

\subsection{Dynamic-Mechanical Thermal Analysis. Typical DMA} curves of the several foamed nanocomposites are presented in the two considered measured directions, that is, parallel (P) and perpendicular $(\mathrm{N})$ to the foam's surface, in Figure 6.

At low strain values, the main mechanisms governing the materials response are bending and stretching of the cell walls, thus enabling the study of the viscoelastic relaxations of the polymer matrix. Such is the case of the glass transition temperature $\left(T_{\mathrm{g}}\right)$, that accounts for the glassrubber relaxation of the amorphous portions of the material. Considering that all the foams analyzed here displayed similar expansion ratios, it was possible to analyze the effects of the MMT nanoparticles and carbon nanofibres on the viscoelastic behaviour of the foams.

In the case of the CNF-reinforced nanocomposites, as seen in Table 2, the glass transition temperature $\left(T_{\mathrm{g}}\right)$ raised with increasing the amount of nanofibres, from the $5.2^{\circ} \mathrm{C}$ of the 5 wt. $\%$ CNF solid to the 7.3 and $7.5^{\circ} \mathrm{C}$, respectively, of the 10 and 20 wt.\% CNF solid nanocomposites. This is the direct result of a higher crystallinity (lower amorphous fraction) and less matrix mobility due to the presence of the nanofibres. Nevertheless, its value decreased with foaming for all the materials.

As expected, the storage modulus $\left(E^{\prime}\right)$ increased with increasing the amount of carbon nanofibres. In the particular case of the foams, the storage modulus only slightly increased with CNF's content for similar relative densities. Nonetheless, the specific storage modulus, that is, the storage modulus relative to the foam's density, increased considerably with adding a higher amount of nanofibres (from the around $800 \mathrm{MPa} \cdot \mathrm{cm}^{3} / \mathrm{g}$ of the $5 \mathrm{wt} . \% \mathrm{CNF}$ foams to the

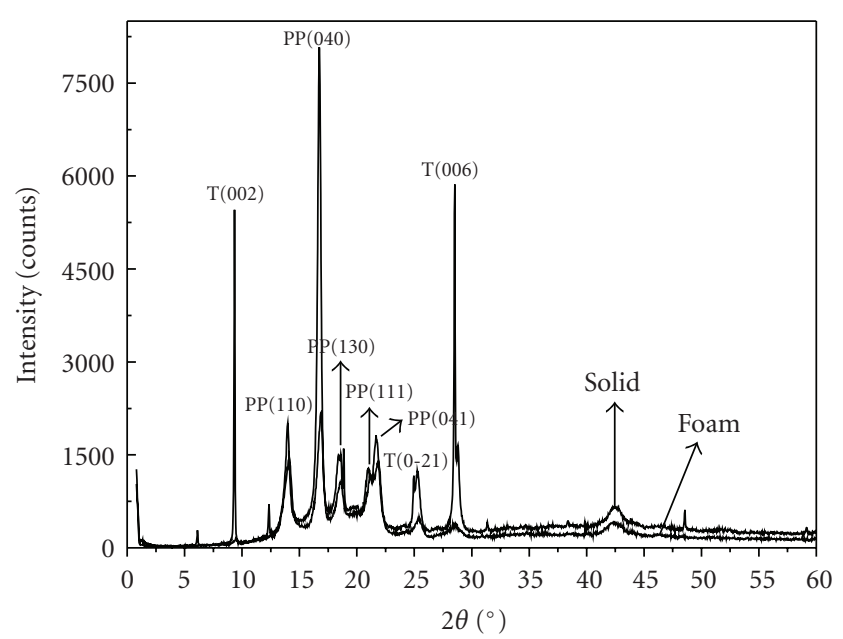

(a)

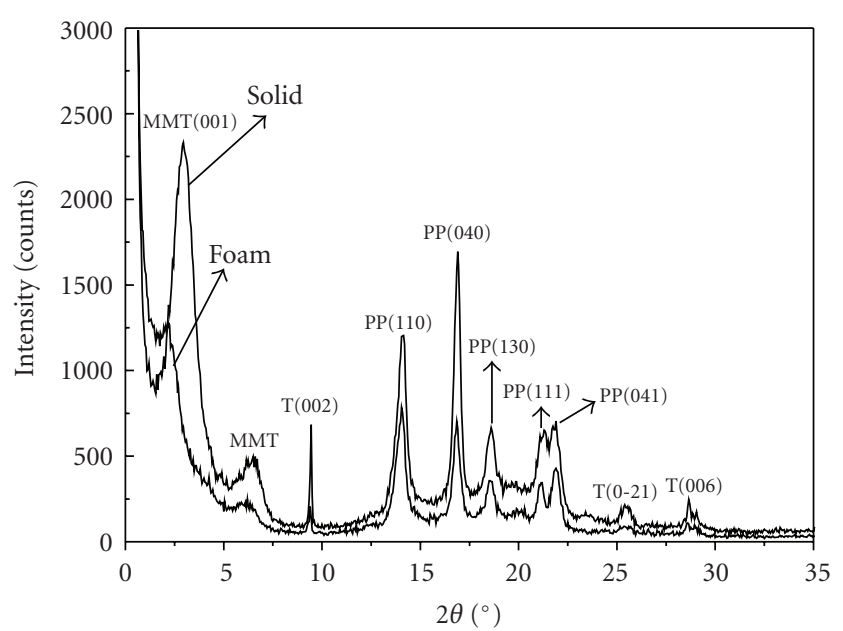

(b)

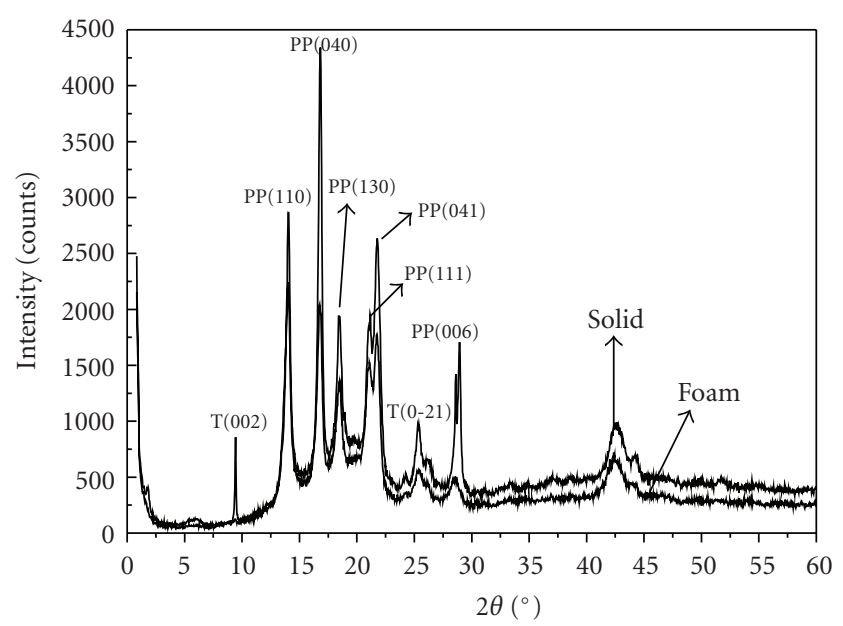

(c)

FIGURE 4: Typical WAXS spectra of the solid and foamed (a) unfilled PP, (b) PP-MMT and (c) PP-CNF nanocomposites. 


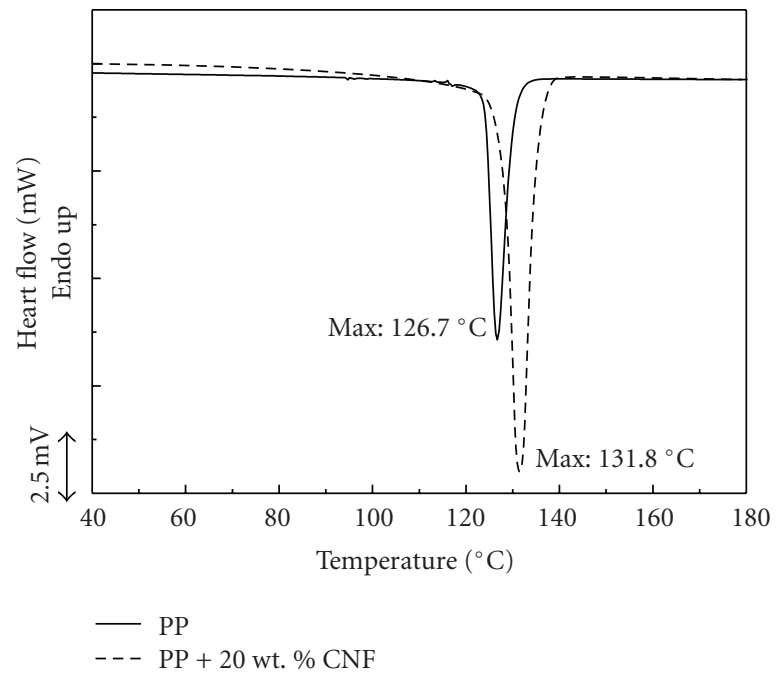

(a)

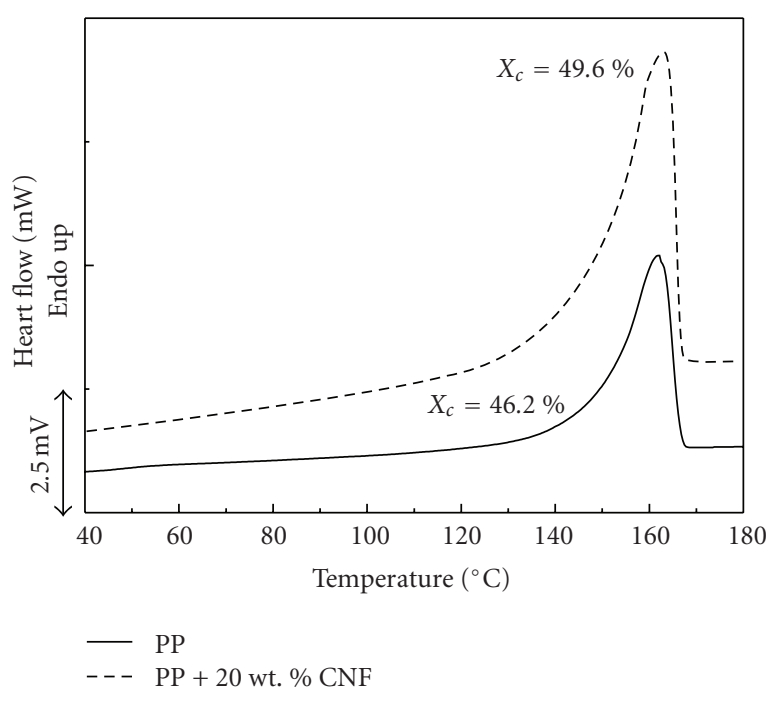

(b)

FIGURE 5: Comparative differential scanning calorimetry between the unfilled and 20 wt.\% CNF PP foams showing (a) the peak's maximum crystallization temperatures and (b) crystallinity determination.

$1200 \mathrm{MPa} \cdot \mathrm{cm}^{3} / \mathrm{g}$ of the $20 \mathrm{wt} . \% \mathrm{CNF}$ ones), indicating the carbon nanofibres efficiency as mechanical reinforcements.

Although displaying almost the same storage modulus than similar relative density unfilled PP foams, comparing the specific value, it is noticeable the reinforcement effect of the montmorillonite particles, with a more than $30 \%$ increase.

A parameter $S$, defined as the specific storage modulus in the parallel direction divided by that in the perpendicular direction was determined as to ascertain the isotropic mechanical properties of the foamed composites. As can be seen by the values presented in the last column of Table 2, the MMT- and CNF-reinforced foams presented a more isotropic mechanical behaviour, especially the PPMMT nanocomposite foams, displaying an $S$ value of 1 , result of their finer isotropic-like cellular structure.

Generally speaking, the MMT nanocomposite foams displayed loss factor values $(\tan \delta)$ slightly higher than the unfilled ones. Taking into account the high densities of the nanocomposite foams and these less importance of the gas enclosed inside the cells, these slight differences may be attained to the different microstructures of the polymer present in the cell walls, as has been previously shown in the partially exfoliated MMT nanoparticles to induce a higher crystallinity and less crystal anisotropy in the PP.

3.4. Electrical Conductivity Measurements. The carbon nanofibres were initially added with the main objective of developing new conductive lightweight materials. With that in mind, measurements of the electrical conductivity of the several solid and foamed PP-CNF nanocomposites were performed over a wide range of frequencies.

Figure 7 presents the broadband electrical conductivity values of the several solid and foamed nanocomposites as a function of frequency.
In the case of a 5 wt. $\%$ CNF content the electrical conductivity of the solids and foams followed a linear behaviour with frequency characteristic of insulating materials such as $\operatorname{PP}\left(\sigma_{\mathrm{PP}} \approx 10^{-16} \mathrm{~S} \cdot \mathrm{cm}^{-1}\right)$. This indicates that the electrical properties of the composite are being controlled by the matrix, as the nanofibres are clearly too far apart to allow electrical conduction. Nonetheless, for a $10 \mathrm{wt} . \%$ CNF concentration the materials started to show a characteristic electrical conduction behaviour, displaying a critical frequency $\left(\nu_{\mathrm{c}}\right)$ below which conductivity gets frequency independent (known as the direct current conductivity, $\sigma_{\mathrm{dc}}$ ). For comparative purposes, the dc conductivity $\left(\sigma_{\mathrm{dc}}\right)$ was always taken at the same frequency $\left(10^{-1} \mathrm{~Hz}\right)$.

Comparatively, foams reached a dc conductivity value earlier than the solid materials. For instance, the $10 \mathrm{wt} . \%$ CNF foam displayed a value of $1.06 \times 10^{-7} \mathrm{~S} / \mathrm{cm}$, considerably higher than the $1.22 \times 10^{-11} \mathrm{~S} / \mathrm{cm}$ of the respective solid. Nevertheless, this conductivity value is still low based on the theoretical value and amount of nanofibres as well as compared to other polymer systems [25]. In these cases, there is a critical concentration of filler, known as the percolation threshold, $\phi_{c}$, where the formation of a $3 \mathrm{D}$ conductive network results in an abrupt increase in the electrical conductivity [30]. It has been shown that the electrical efficiency of these conductive fillers depends on the presence of polymer chains between contacts, and particularly on local crystal formation. Electrical conduction considerably decreases in the crystalline regions compared to the amorphous ones, where ion conductivity is the dominating conduction mechanism [31-33]. These particularities act to the formation of electrical resistances between the nanofibres, limiting an effective electrical conduction by percolation. Under these conditions, a model based on tunnelling conduction fits better to the analyzed system, with the $\mathrm{dc}$ conductivity being depicted by $\sigma_{\mathrm{dc}} \propto \exp (-A d)$ $[34,35]$, where $A$ is a tunnel parameter and $d$ is the 


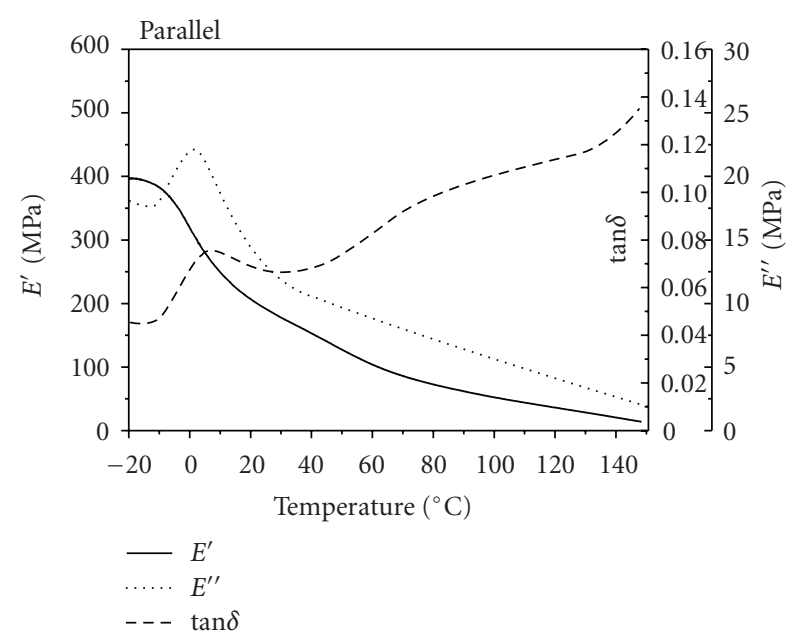

(a)

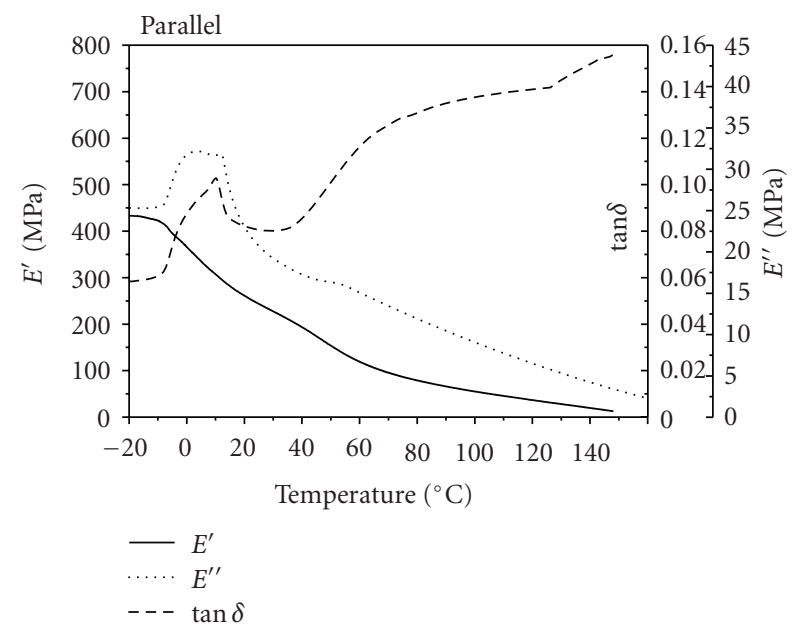

(c)

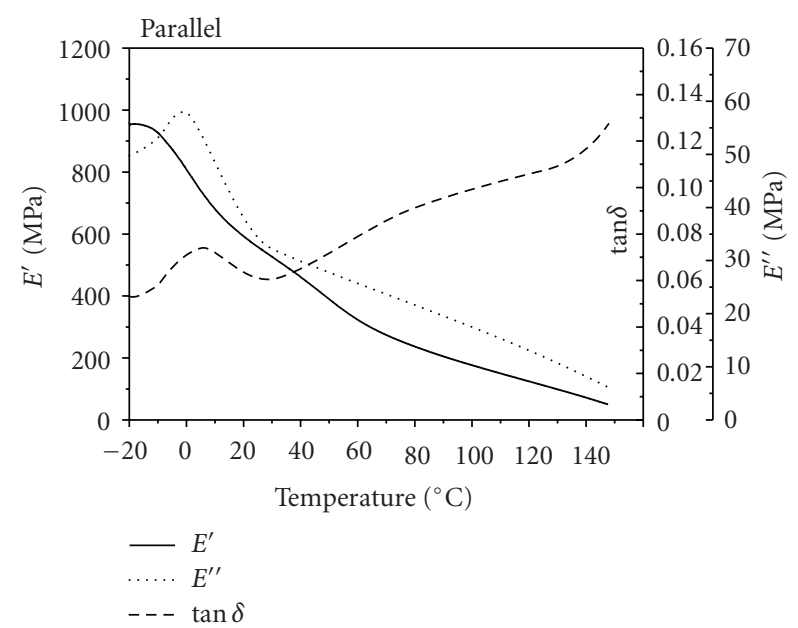

(e)

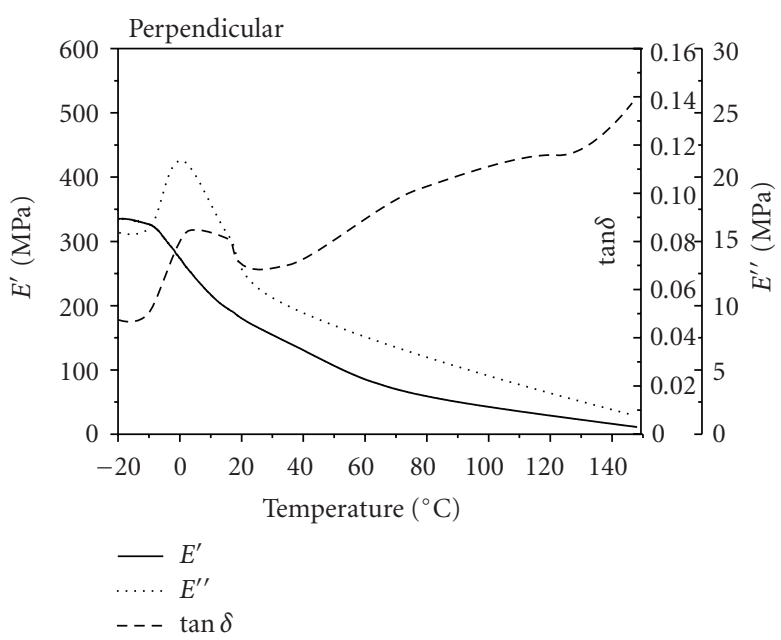

(b)

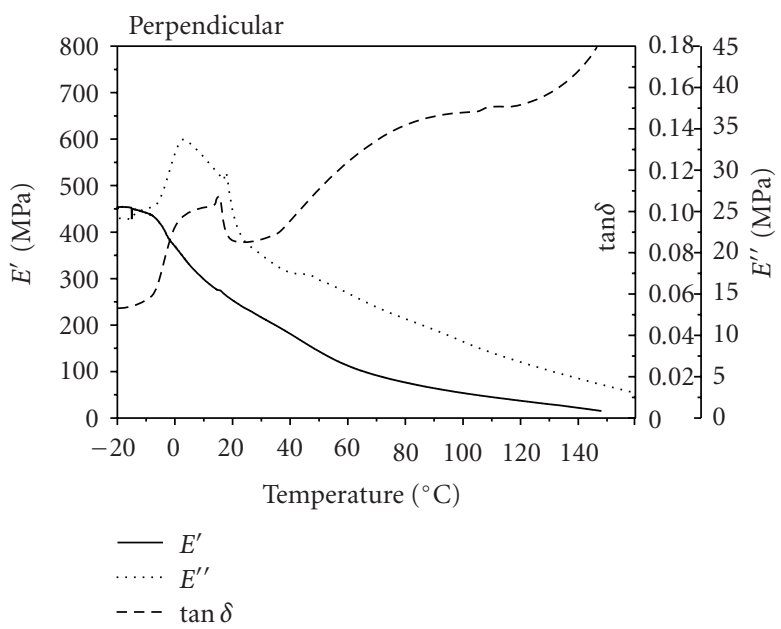

(d)

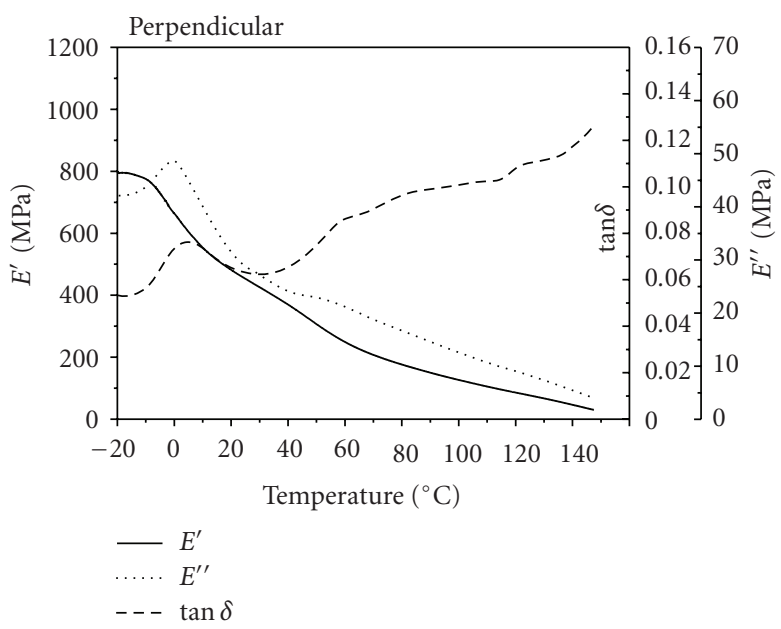

(f)

Figure 6: Typical DMA curves of the unfilled PP foams, (a) and (b); PP-MMT foams, (c) and (d); PP-20\% CNF foams, (e) and (f). 
TABLE 2: DMA results of the solid and foamed unfilled, MMT, and CNF-reinforced PP foams.

\begin{tabular}{|c|c|c|c|c|c|}
\hline Material & Direction & $T_{\mathrm{g}} *\left({ }^{\circ} \mathrm{C}\right)$ & $E^{\prime}$ at $20^{\circ} \mathrm{C}(\mathrm{MPa})$ & Specific modulus $\left(\mathrm{MPa} \cdot \mathrm{cm}^{3} \cdot \mathrm{g}^{-1}\right)$ & $S$ \\
\hline \multirow{3}{*}{ PP } & Solid & 5.4 & 1961.3 & 2114.4 & - \\
\hline & $\mathrm{P}$ & 6.6 & 206.5 & 676.3 & \multirow{2}{*}{1.1} \\
\hline & $\mathrm{N}$ & 4.7 & 179.9 & 589.2 & \\
\hline \multirow{3}{*}{ PP-MMT } & Solid & 6.0 & 2010.0 & 2152.0 & - \\
\hline & $\mathrm{P}$ & 5.6 & 261.5 & 839.9 & \multirow{2}{*}{1.0} \\
\hline & $\mathrm{N}$ & 5.9 & 252.7 & 823.1 & \\
\hline \multirow{3}{*}{ PP-5\% CNF } & Solid & 5.2 & 1827.5 & 2006.0 & - \\
\hline & $\mathrm{P}$ & 4.5 & 235.4 & 801.5 & \multirow{2}{*}{1.1} \\
\hline & $\mathrm{N}$ & 2.5 & 209.6 & 713.6 & \\
\hline \multirow{3}{*}{ PP-10\% CNF } & Solid & 7.3 & 2300.3 & 2532.6 & - \\
\hline & $\mathrm{P}$ & 6.9 & 231.4 & 806.6 & \multirow{2}{*}{0.7} \\
\hline & $\mathrm{N}$ & 5.2 & 328.6 & 1100.9 & \\
\hline \multirow{3}{*}{ PP-20\% CNF } & Solid & 7.5 & 2732.7 & 2832.1 & - \\
\hline & $\mathrm{P}$ & 4.5 & 543.5 & 1230.0 & \multirow{2}{*}{1.0} \\
\hline & $\mathrm{N}$ & 4.3 & 473.6 & 1185.5 & \\
\hline
\end{tabular}

${ }^{*} T_{\mathrm{g}}$-Glass transition temperature measured in $\tan \delta$.

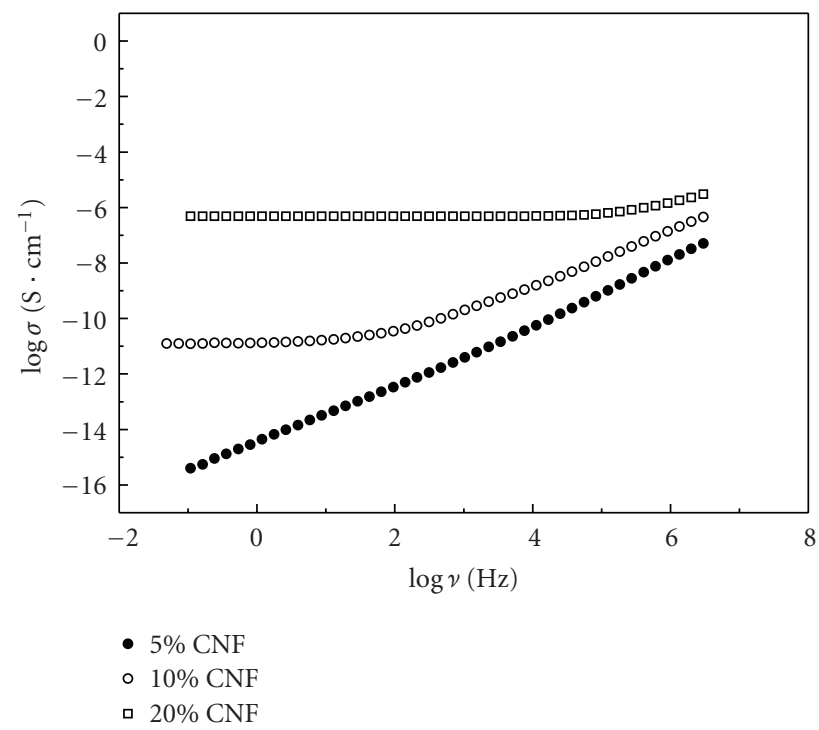

(a)

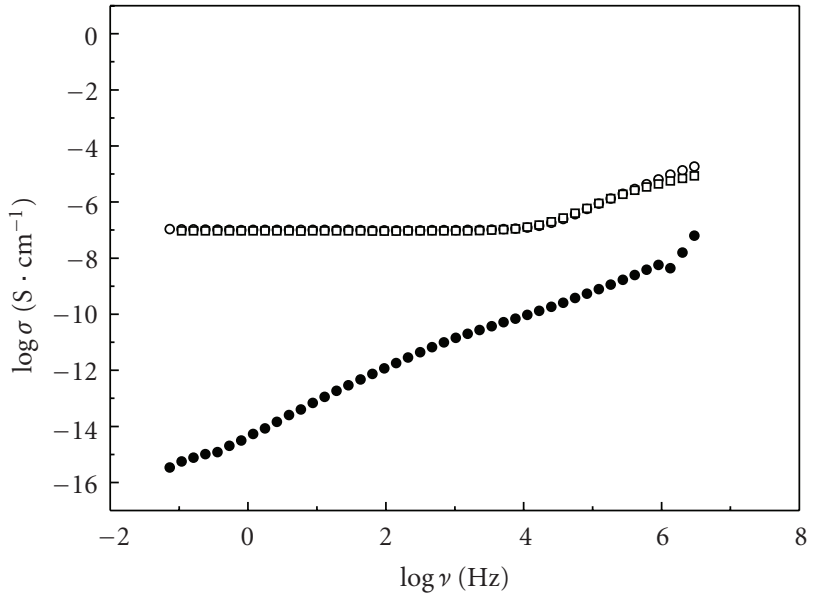

- $5 \% \mathrm{CNF}$

- $10 \% \mathrm{CNF}$

- $20 \% \mathrm{CNF}$

FIGURE 7: Broad-band electrical conductivity $(\sigma)$ as a function of frequency $(\nu)$ for the (a) solid, and (b) foamed PP-CNF nanocomposites.

so-called tunnel distance. This predominant tunnelling conduction behaviour has been previously shown in other research works to be typical of carbon nanofibre polyolefin nanocomposites, due to fibre breaking during processing the dispersed short carbon nanofibres making it a lot harder to reach a direct contact between the fibres at low contents [36]. Using the tunnelling conduction approach, the theoretical critical concentration of nanofibres for electrical conduction for the nanocomposite foams was found to be $10 \mathrm{wt} . \%$ lower than the $12 \mathrm{wt} . \%$ determined for the solids, indicating that the foaming process is adding to a higher nanofibre functionality due to improved dispersion (see Figure 3(f)).

\section{Conclusions}

This work presents the preparation and preliminary characterization of montmorillonite and carbon nanofibrereinforced rigid polypropylene foams, with the objective of developing new multifunctional lightweight materials for structural applications.

Regarding the foaming behaviour and cellular structure of the foams, the incorporation of MMT and CNF resulted in finer isometric-like cellular structures, especially noticeable for the MMT nanocomposite foams. This was attained to a cell nucleation effect, supported by the higher crystallization temperatures and crystallinities. In the case of the PP-CNF 
foams, increasingly smaller cell sizes were observed for similar expansion ratios with increasing the amount of nanofibres.

The nanofillers, adding to the foaming process, totally erased the preferential crystal orientation of the $\alpha$-PP's crystal observed in the unfilled solid and in a lesser extent in the unfilled PP foams ( $b$ lattice parallel to the sample's surface). Although the FWHM values of the unfilled PP increased with foaming, the incorporation of the nanofillers promoted the opposite effect, related to a higher crystalline perfection.

The dynamic-mechanical behaviour of the unfilled and nanocomposite polypropylene foams showed that the nanofillers acted as mechanical reinforcements, increasing the specific storage moduli of the foams. They also promoted a more isotropic-like mechanical behaviour, especially the MMT nanoparticles, related to a finer isotropic cellular structure of the nanocomposite foams.

As a previous step to the study of incorporating conductive nanofillers on the electrical conduction behaviour of PP foams, electrical conductivity measurements were performed on the different solid and foamed PP-CNF nanocomposites. Interesting results were found with foaming the nanocomposites, the foams displaying a higher electrical conductivity than their solid counterparts, indicating that foaming may come as a useful tool in creating an electrically-conductive network.

\section{Acknowledgments}

The financial assistance from the Spanish Ministry of Science and Education for the project MAT2007-62956 is gratefully acknowledged. The authors would like to thank Professor Miguel Mudarra for all the help with the electrical conductivity measurements.

\section{References}

[1] M. A. Rodríguez-Pérez, "Crosslinked polyolefin foams: production, structure, properties, and applications," Advances in Polymer Science, vol. 184, pp. 97-126, 2005.

[2] C. B. Park and L. K. Cheung, "A study of cell nucleation in the extrusion of polypropylene foams," Polymer Engineering and Science, vol. 37, no. 1, pp. 1-10, 1997.

[3] Sekisui Alveo, Product Guide, Sekisui Alveo, Roermond, The Netherlands, 2003.

[4] S. Tokuda and T. Kemmotsu, "Electron beam irradiation conditions and foam seat properties in polypropylenepolyethylene blends," Radiation Physics and Chemistry, vol. 46, no. 4-6, pp. 905-908, 1995.

[5] P. Spitael, C. W. Macosko, and A. Sahnoune, "Extensional rheology of polypropylene and its effect on foaming of thermoplastic elastomers," in Proceedings of the Annual Technical Conference (ANTEC '02), pp. 1792-1796, Society of Plastics Engineers, San Francisco, Calif, USA, 2002.

[6] M. Antunes, J. I. Velasco, V. Realinho, and E. Solórzano, "Study of the cellular structure heterogeneity and anisotropy of polypropylene and polypropylene nanocomposite foams," Polymer Engineering and Science, vol. 49, no. 12, pp. 24002413, 2009.
[7] N. Mills, Polymer Foams Handbook. Engineering and Biomechanics Applications and Design Guide, Elsevier, Oxford, UK, 1st edition, 2007.

[8] D. Klempner and V. Sendijarevic, Polymeric Foams and Foam Technology, Hanser, Munich, Germany, 2nd edition, 2004.

[9] R. R. Puri and K. T. Collington, "The production of cellular crosslinked polyolefins. 2. The injection-molding and press molding techniques," Cellular Polymer, vol. 7, pp. 219-231, 1988.

[10] UK Zotefoams. High Performance Polymers, October 1999.

[11] D. Eaves, Handbook of Polymer Foams, Rapra Technology, Shawbury, UK, 2004.

[12] M. Antunes, V. Realinho, and J. I. Velasco, "Study of the influence of the pressure drop rate on the foaming behaviour and dynamic-mechanical properties of $\mathrm{CO}_{2}$ dissolution microcellular polypropylene foams," Journal of Cellular Plastics. In press.

[13] J. I. Velasco, M. Antunes, O. Ayyad, et al., "Foaming behaviour and cellular structure of LDPE/hectorite nanocomposites," Polymer, vol. 48, no. 7, pp. 2098-2108, 2007.

[14] J. E. Martini, N. P. Suh, and F. A. Waldman, US patent 4,473,665, 1984.

[15] L. J. Lee, C. Zeng, X. Cao, X. Han, J. Shen, and G. Xu, "Polymer nanocomposite foams," Composites Science and Technology, vol. 65, pp. 2344-2363, 2005.

[16] C. Zeng, X. Han, L. J. Lee, K. W. Koelling, and D. L. Tomasko, "Polymer-clay nanocomposite foams prepared using carbon dioxide," Advanced Materials, vol. 15, no. 20, pp. 1743-1747, 2003.

[17] Y. Di, S. Iannace, E. Di Maio, and L. Nicolais, "Poly(lactic acid)/organoclay nanocomposites: thermal, rheological properties and foam processing," Journal of Polymer Science-Part $B$, vol. 43, no. 6, pp. 689-698, 2005.

[18] X. Han, C. Zeng, L. J. Lee, K. W. Koelling, and D. L. Tomasko, "Extrusion of polystyrene nanocomposite foams with supercritical $\mathrm{CO}_{2}$," Polymer Engineering and Science, vol. 43, no. 6, pp. 1261-1275, 2003.

[19] M. Okamoto, P. H. Nam, P. Maiti, et al., "Biaxial flowinduced alignment of silicate layers in polypropylene/clay nanocomposite foam," Nano Letters, vol. 1, no. 9, pp. 503-505, 2001.

[20] M. Lee, B.-K. Lee, and K.-D. Choi, "Foam compositions of polyvinyl chloride nanocomposites," WO/2004/074357, International Application No.: PCT/KR2004/000328. 2004.

[21] J. Shen, X. Han, and L. J. Lee, "Nucleation and reinforcement of carbon nanofibers on polystyrene nancomposite foam," in Proceedings of the 63rd Annual Technical Conference (ANTEC '05), vol. 7, pp. 117-121, November 2005.

[22] M. Antunes, V. Realinho, A. B. Martínez, E. Solórzano, M. A. Rodríguez-Pérez, and J. I. Velasco, "Heat transfer of mineralfilled polypropylene foams," Defect and Diffusion Forum, vol. 297-301, pp. 990-995, 2010.

[23] M. Antunes, J. I. Velasco, V. Realinho, and D. Arencón, "Characterization of carbon nanofibre-reinforced polypropylene foams," Journal of Nanoscience and Nanotechnology, vol. 10, pp. 1241-1250, 2010.

[24] M. Antunes, V. Realinho, E. Solórzano, M. A. RodríguezPérez, J. A. de Saja, and J. I. Velasco, "Thermal conductivity of carbon nanofibre-polypropylene composite foams," Defect and Diffusion Forum, vol. 297-301, pp. 996-1001, 2010.

[25] M. Shaffer and J. Sandler, "Carbon nanotube/nanofibre polymer composites," in Processing and Properties of Nanocomposites, S. Advani, Ed., pp. 1-59, World Scientific, River Edge, NJ, USA, 2006. 
[26] G. L. A. Sims and C. Khunniteekool, "Cell size measurement of polymeric foams," Cellular Polymers, vol. 13, no. 2, pp. 137146, 1994.

[27] B. Wunderlich, Thermal Analysis, Academic Press, New York, NY, USA, 1990.

[28] J. Sandler, G. Broza, M. Nolte, K. Schulte, Y.-M. Lam, and M. S. P. Shaffer, "Crystallization of carbon nanotube and nanofiber polypropylene composites," Journal of Macromolecular Science, vol. 42, no. 3-4, pp. 479-488, 2003.

[29] J. I. Velasco, C. Morhain, A. B. Martínez, M. A. RodríguezPérez, and J. A. de Saja, "The effect of filler type, morphology and coating on the anisotropy and microstructure heterogeneity of injection-moulded discs of polypropylene filled with aluminium and magnesium hydroxides. Part 1. A wide-angle X-ray diffraction study," Polymer, vol. 43, no. 25, pp. 68056811, 2002.

[30] D. Stauffer and A. Aharony, Introduction to Percolation Theory, Taylor \& Francis, London, UK, 2nd edition, 2003.

[31] P. Pötschke, M. Abdel-Goad, I. Alig, S. Dudkin, and D. Lellinger, "Rheological and dielectrical characterization of melt mixed polycarbonate-multiwalled carbon nanotube composites," Polymer, vol. 45, no. 26, pp. 8863-8870, 2004.

[32] I. Alig, S. M. Dudkin, W. Jenninger, and M. Marzantowicz, "Ac conductivity and dielectric permittivity of poly(ethylene glycol) during crystallization: percolation picture," Polymer, vol. 47, p. 1722, 2006.

[33] I. Alig, D. Lellinger, S. M. Dudkin, and P. Pötschke, "Conductivity spectroscopy on melt processed polypropylenemultiwalled carbon nanotube composites: recovery after shear and crystallization," Polymer, vol. 48, no. 4, pp. 1020-1029, 2007.

[34] E. K. Sichel, J. I. Gittleman, and P. Sheng, "Tunneling conduction in carbon-polymer composites," in Carbon Black Polymer Composites: The Physics of Electrically Conducting Composites, E. K. Sichel, Ed., Marcel Dekker, New York, NY, USA, 1982.

[35] N. Ryvkina, I. Tchmutin, J. Vilčáková, M. Pelíšková, and P. Sáha, "The deformation behavior of conductivity in composites where charge carrier transport is by tunneling: theoretical modeling and experimental results," Synthetic Metals, vol. 148, no. 2, pp. 141-146, 2005.

[36] A. Linares, J. C. Canalda, M. E. Cagiao, et al., "Broadband electrical conductivity of high density polyethylene nanocomposites with carbon nanoadditives: multiwall carbon nanotubes and carbon nanofibers," Macromolecules, vol. 41, no. 19, pp. 7090-7097, 2008. 

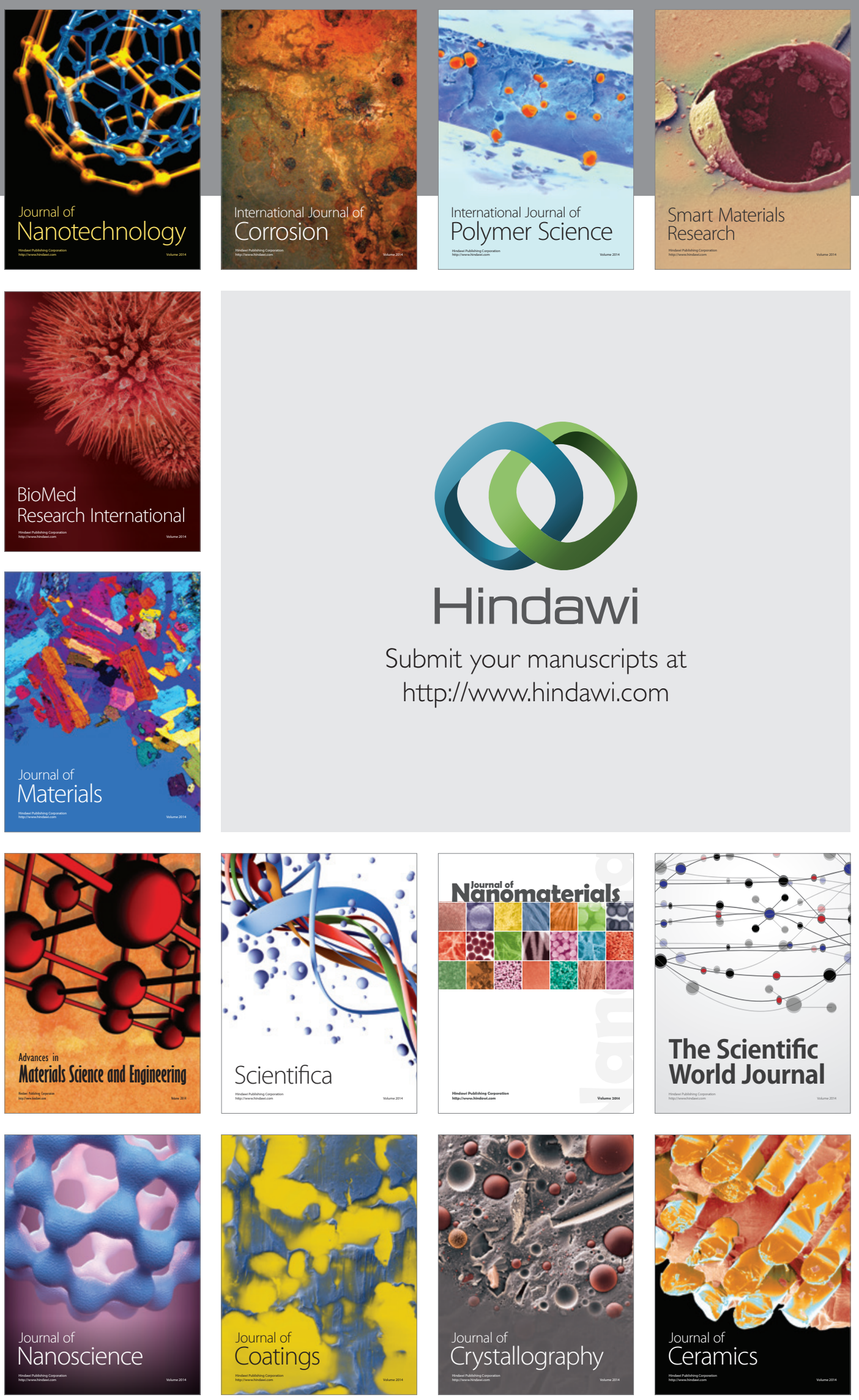

The Scientific World Journal

Submit your manuscripts at

http://www.hindawi.com

\section{World Journal}

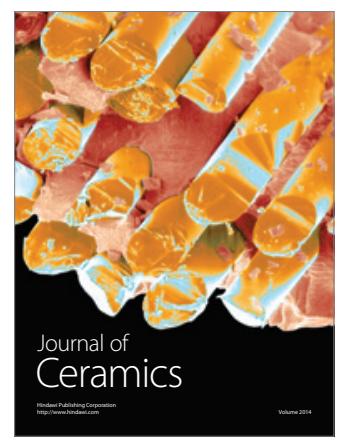

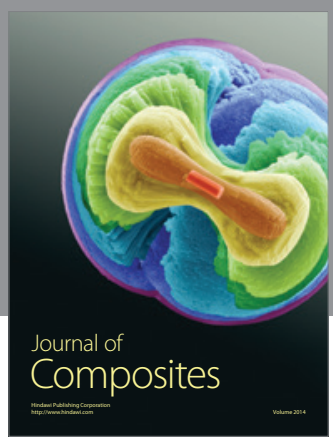
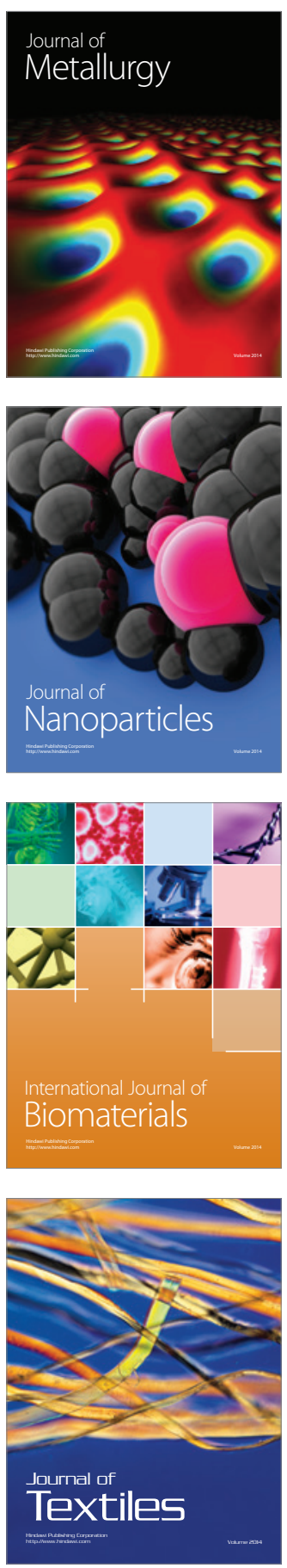